DERDRTAMENTO DE ANATOMHA PATOLGGICA

Direlor: l'rof. Dr. Luclydes Onofre Martins

\title{
NOTAS PRELIMINARES SÔBRE A PESQUISA DE RESTOS EMBRIONĀRIOS EM SUPRA-RENAIS NORMAIS DOS ANIMAIS DOMÉSTICOS
}

\author{
Eicl.yoles Onofre: Maktins \\ Calcelritico
}

\author{
Antonio G. Ferki \\ Assistente
}

1 estampa (2 gravuras)

(): restos cmbrionírios que permantecm nos lecidos ou órgäos yerfeitamente desenvolvidos ou que são encontrados deslocados de sua posição normal, foram responsabilizados. por muitos autores, cono sendo a causa das neoplasias.

Fimbora esta idécia já existisse há muito tempo, somente ganhou vulto com (1) trabalhos de Cohnutus, surgindo entâo a teoria embrionária para cxplicar a gennese dos tumores. A teoria de Conshem obteve grande numero de adeptos; entre os quais Willinas, Libinsch, Wilms, Ribblant e Meyer.

Nodernamente esta teoria tem suas limitaçôes na explicação da oncogênesc, mas a grande maioria dos patologistas admile que os restos embrionários cons. tituem terreno propício para a cancerização.

Com isto năo se quer dizer que todo resto embrionário evolucione para uma ncoplasia. rile pode permanecer cstacionário por tôda a vida se não houver uma (ausa que desencadeie sua proliferação.

A calu:a da proliferação àus restos emisrionários permanece na mesma obscuridade da caussa do câncer em geral.

Recentemente um de nús '(Martiss). estudando os tumores da medular sil. pra-renal de hovinos, observou que o aspecto microscópico dêsses blastomas era de constituiçáo semelhante a dos restos embrionários, e os responsabilizou pelo desenvolvimento da neoplasia,

l'ara melhor compreensão da explicação do encontro dêsses restos embrio. nários, recordamos aqui a embriologia da medular supra-renal.

A porgão medular loma sua origem no cotoderma neural, partindo de duas formaçües paramedianas. Nos hordos da goleira neural, quando esta está ligada ainda ao folhèo ectodérmico, observámos uma intensa proliferação de célu. las que se distinguem das do eshô̧̧o nervoso por se apresenturem mais claras 
e mais ou menos arreciondadas; êsse grupo celular constitui a crista ganglionar. Logo depois, a goteira neural se fecha para formar o canal medular, passando essas células então a constituir um grupaniento sólido em forma de cunha encravado no canal medular. Em seguida a crista ganglionar cinde-se longitudinalmente em duas metades que se deslocam, respectivannente, para a direita e para a esquerda, por baixo do ectoderma entre o miótomo e o tubo nervoso. As duas cristas laterais derivadas do desdobrantento da primitiva crista ganglionar impar, sofrem, a scguir, um processo de segenentação em outras tuntas formaçōes intervaladas, correspondentes aos somiios. Há, entảo, intensa multiplicuçüu e diferenciaşäo das células das cristas ganglionares, que se agloneram pura formar os esboģos dos geânglios espinhais que. desde logo se scparam da critita e do canal medular.

Da diferenciação dêsses elementos epiteliais da crista gang̣lionar surge uına geração de células pequenas, de aspecto linf́cicitíde, com núcleo escuro, rico $\mathrm{cm}$ cromatina, com estreita bainha citoplásmica: são as simpatog̣ônias. İstas lìm capacidade bipotencial e podem, portanto, cvoluir para duas séries difercntes: de um lado, para súrie simpática, dando, respectivamente, o simpatoblasto e o simpatócito; de outro lacio, para a série cromafim, dando o fcocromoblasto e o feocromócito. As simpatogônias sāo dotadas de capacidade migradora e partin. do da crista ganglionar, dirigem-se para o seio do mesênquima ventral para formar, pela diferenciação já referida, os gânglios simpáticos e os plexos simpáticos viscerais, enquanto a diferenciação do mesênquima ambiente dá luğar ao componente conectivo do gânglio. Na questão que nos interessa, depois das simpatogônias atingirem o esbôço da cortical supra-renal, sofrem a diferenciação no sentido cromafim, resultando a medular do mesmo órgäo. $\Lambda$ maioria dos embriologistas aceita esta embriogènese da supra-renal, mas alguns autores, como CaMus, admitem a derivaçāo mesenquimal.

O material por nós estudado era proveniente dos matadouros e do Instituto Pinheiros. Esse material foi fixado em formol a $10 \%$, incluido em parafina, corado pela hematoxilina e cosina e impregnado pelo método de Bielschowsky e de cada supra-renal foram feitos três blocos e examinadas duas lâminas de cada bloco.

Examinando 106 supra-renais normais de bovinos e 50 de eqüinos obtivemos os resultados que se acham resumidos no quadro abaixo.

\begin{tabular}{c|c|c|c}
\hline \multicolumn{1}{c|}{ Espécie } & Simpatócitos & Simpatogônias & F'cocromoblitstos \\
\hline \hline Bovina $\ldots \ldots \ldots \ldots$ & 28 & 26 & - \\
Eqüina $\ldots \ldots \ldots \ldots$ & 11 & 3 & 5 \\
\hline
\end{tabular}


$O_{5} 51$ restos embrionírios foran encontrados em 44 supra-renais de bovinos e os 19 foram encontrados em 15 supra-renais de eqüinos.

Nos bovinos, os simpatócitos se apresertlavam ora em blocos, ora em blocos circundados por tecido neurofibrilar, ora esparsos entre cordōes de feocromócitos, ora esparsos por tôda a porção medular. Encontrámos ainda os simpatócitos junto à cápsula do órgão, no meio de tecido cromafim ou reunidos, assemelhando-se a um gânglio simpático ou em blucos, num dos quais várias células se upresentavam en divisão amitótica. As simpatogônias foram encontradas em focos, sendo que um dêles se continuava com um bloco de neuroblastos; em outros, o foco de simpatogônia se apresentava circundando um bloco de células nervosas e, em outro ainda, além dos focos de simpatogônias localizadas na medular, observamos un foco em plena cortical junto à cápsula.

Nos eqiüinos, os simpatócitos sc apresentavam ora isolados, ora em blocos circundados por tecido neurofibrilar. As simpatogônias foram encontradas sempre em focos e localizadas na medular, e os feocromoblastos foram observados em blocos em plena medular.

$O$ resultado destas observações preliminares sugere que a permanência de restos embrionários nas supra-renais normais tanto de bovinos como de eqüinos é freqüente.

\section{BHIBIJOGRAFIA}

Camus, R. - "in" Van Campenhout, E. - 1930 - Historical survey of the development of the sympathetic nervous system. Quart. Rev. Biol., 5(2):34

Connm:lм - "in" Libbert, H. - Stenberg, C. - 1933 - Tratado de Patologia General y Anatomia Patologica: 170-7. 2* ed. Barcelona, Labor S/A.

Lomarscu - "in" lswing, J. -- 1948 - Oncologia: S1-100. Barcelona, Salvat Ed. S/A.

Martiss, F. O. - 1951 - l'umores primitivos da medular supra-renal de bovinos. Tese, Fice, Mied. Vet. U. S. Paulo

M:Y̌н - "in" Ewing, J. - 1948 - Oncologia: 81-100. IBarceluna, Salvat Ed. S/A.

Rinzsiz, H. - "in" Ribbert, II. - Sternberg, C. - 1933 - - Tratado de Patolngia General y Anatomia Patologica: 170-7. 20 ed. I3arcelona, Labor $\mathrm{S} / \mathrm{A}$.

Wilr.1Axs - "in" Ewing, J. - 1948 - Oncologia: 81-100. I3arcelona, Salvat Ed. S/A.

Wuxs - "in" Pires, R. F. - 1945 - Tumores disnntogenćticos do córtex renal. Rev. Med. Cir. s. Paulo, B(7-8):1-39 



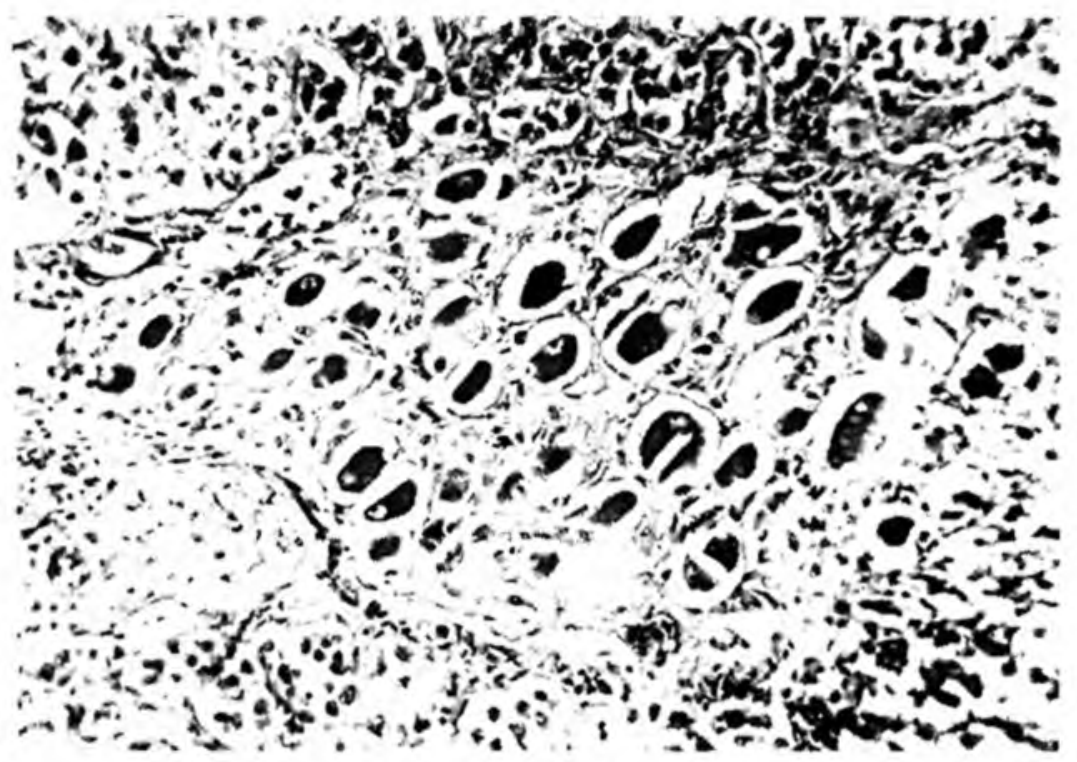

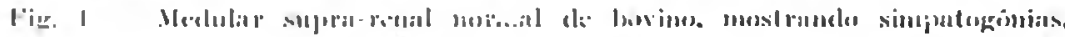

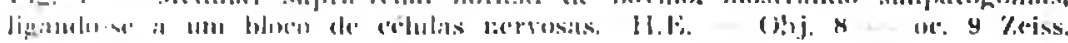

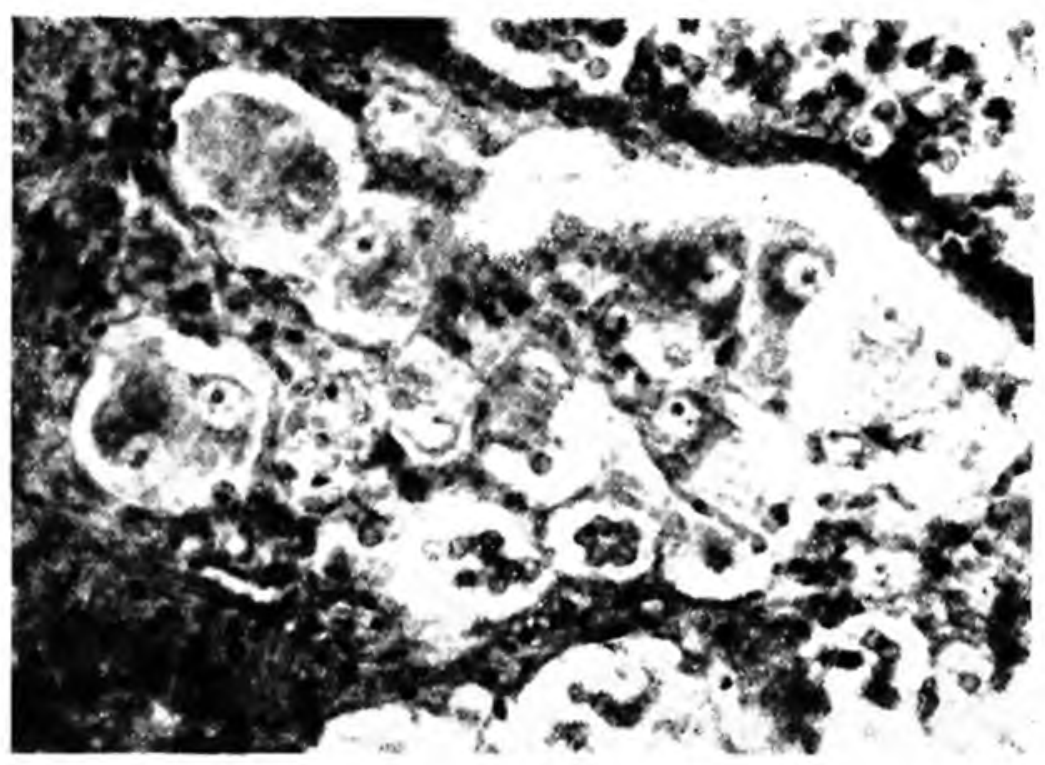

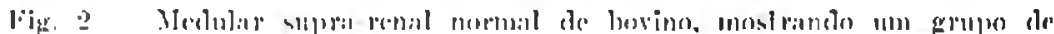

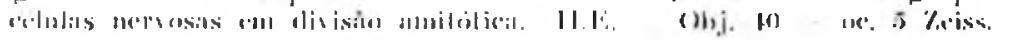

